\title{
BMJ Open Economic burden of schizophrenia in Italy: a probabilistic cost of illness analysis
}

\author{
Andrea Marcellusi, ${ }^{1,2,3}$ Gianluca Fabiano, ${ }^{1,2}$ Raffaella Viti, ${ }^{1}$ \\ Pier Cesare Francesa Morel, ${ }^{4}$ Giuseppe Nicolò, ${ }^{5}$ Alberto Siracusano, ${ }^{6,7}$ \\ Francesco Saverio Mennini ${ }^{1,2}$
}

To cite: Marcellusi A, Fabiano G, Viti $\mathrm{R}$, et al. Economic burden of schizophrenia in Italy: a probabilistic cost of illness analysis. BMJ Open 2018;8:e018359. doi:10.1136/ bmjopen-2017-018359

- Prepublication history and additional material for this paper are available online. To view these files, please visit the journal online (http://dx.doi. org/10.1136/bmjopen-2017018359).

Received 26 June 2017 Revised 7 September 2017 Accepted 8 December 2017

Check for updates

${ }^{1}$ Economic Evaluation and HTA (EEHTA), CEIS University of Rome "Tor Vergata", Rome, Italy ${ }^{2}$ Institute for Leadership and Management in Health, Kingston University London, London, UK ${ }^{3}$ National Research Council (CNR), Institute for Research on Population and Social Policies (IRPPS), Rome, Italy

${ }^{4}$ HEMAR Manager, JanssenCilag SpA, Milano, Italy ${ }^{5}$ Department Salute Mentale e dipendenze patologiche, ASL Roma, Rome, Italy

${ }^{6}$ Department of Systems Medicine, University of Rome "Tor Vergata", Rome, Italy ${ }^{7}$ Psychiatry and Clinical Psychology Unit, Department of Neurosciences, Fondazione Policlinico "Tor Vergata", Rome, Italy

Correspondence to

Mr Gianluca Fabiano; g.fabiano@kingston.ac.uk

\section{ABSTRACT}

Objectives Schizophrenia is a chronic, debilitating psychiatric disease with highly variable treatment pathways and consequent economic impacts on resource utilisation. The aim of the study was to estimate the economic burden of schizophrenia in Italy for both the societal and Italian National Healthcare perspective. Methods A probabilistic cost of illness model was applied. A systematic literature review was carried out to identify epidemiological and economic data. Direct costs were calculated in terms of drugs, hospitalisations, specialist services, residential and semiresidential facilities. Indirect costs were calculated on the basis of patients' and caregivers' loss of productivity. In addition, the impact of disability compensation was taken into account using a database from the Italian National Social Security Institute -Italy (INPS).

Results Overall, 303913 prevalent patients with schizophrenia were estimated. Of these, 212739 (70\%) were diagnosed and $175382(82 \%)$ were treated with antipsychotics. The total economic burden was estimated at $€ 2.7$ billion ( $95 \% \mathrm{Cl} € 1771.93$ to $€ 3988.65$ ), 50.5\% due to indirect costs and $49.5 \%$ to direct costs. Drugs corresponded to $10 \%$ of direct costs and hospitalisations (including residential and semiresidential facilities) accounted for $81 \%$.

Conclusions This study highlighted that indirect costs and hospitalisations (including residential and semiresidential facilities) play a major role within the expenses associated with schizophrenia in Italy, and this may be considered as a tool for public decision-makers.

\section{INTRODUCTION}

Schizophrenia is considered among the most severe and debilitating mental disorders with enormous social and economic costs for the patients, caregivers and society as a whole. ${ }^{1}$ The epidemiological studies report a uniform prevalence rate among the most developed countries $(0.3 \%-0.7 \%) .^{2}{ }^{3}$ The mortality rate is more than double ${ }^{4}$ than that of the general population, mainly due to suicides and cardiovascular diseases, with a higher risk of comorbidity (psychiatric and non-psychiatric) ${ }^{5}$

\section{Strengths and limitations of this study}

- A bottom-up approach was used for estimating direct costs

- Human capital approach was used to calculate indirect costs

- The study may suffer from the standardisation of the retrieved data required to break down the population

The treatment and care of the patients with a diagnosis of schizophrenia accounts for between $1.5 \%$ and $3 \%$ of the total national health expense in the most developed countries, ${ }^{46}$ and $22 \%{ }^{7}$ of the costs associated with mental disorders. In Europe, the economic impact is equal to 93.9 billion, of which $69 \%$ is due to indirect costs only. ${ }^{1}$ In fact, it is estimated that the unemployment rate of patients with schizophrenia is more than double than that of the general population, ${ }^{89}$ and $51 \%$ of them receive a disability pension in Italy. ${ }^{8}$

As a consequence, indirect costs are a key aspect to estimate the overall impact of schizophrenia due to the precocity and chronic course of the illness, arising in most cases during adolescence. ${ }^{10}$ Furthermore, it is fundamental to efficiently allocate the economic resources in the therapeutic area. Therefore, major aspects are also the administration of highly effective drugs and the continuity of treatment. It has been proved, in fact, that non-adherence to drug treatments is related to the flare of psychotic symptoms. This might result in the readmission to psychiatric wards or residential facilities and, consequently, higher costs for the National Health Service (NHS). ${ }^{7}$ For these reasons, non-adherence to treatment is the most common cause of rehospitalisation (about $40 \%$ of new hospital admissions) and the risk of relapses, often characterised by episodes of greater severity. ${ }^{71112}$ 
This study was aimed at measuring the economic impact of schizophrenia in Italy, estimating the direct and indirect costs linked to the treatment, care and management of the diagnosed patients. The purpose was to conduct a systematic analysis of the existing literature and to create a probabilistic model to assess the annual economic burden for the NHS and for the society as a whole. The aim of this work was to present an overview of the resources used for the treatment and management of patients with schizophrenia in Italy. The estimation of the annual economic burden may be considered as an insight in order to improve both the efficacy and effectiveness of the patient care.

\section{METHODS}

A prevalence-based probabilistic model was used to calculate the aggregate measure of the economic impact associated with schizophrenia. Similar models have been previously applied in many studies and searches in the field of health economics evaluation ${ }^{13-22}$ to represent a 1-year static estimation of the economic burden due to disease.

A bottom-up approach was used for estimating the total economic burden of schizophrenia from the societal perspective in Italy. This measure was obtained by taking into account the average costs per treatment multiplied by the prevalence of the population. Furthermore, the human capital approach was used to calculate indirect costs, considering the loss in productivity of both patients and their caregivers. Data included in the model were obtained from a systematic literature review conducted on the basis of the Preferred Reporting Items for Systematic Reviews and Meta-Analyses ${ }^{23}$ (online supplementary appendix, figure 1). The research was conducted in November 2015, and the last 10-year publications were examined. The analysis was performed through the online MEDLINE (Medical Literature Analysis and Retrieval
System) bibliographic archive of MEDLARS, using the PubMed search system. In order to retrieve robust data specifically referred to the Italian context, the inquiry was integrated with the use of Google Scholar search engine and the database of the Italian specialised magazine reviews, along with the sources available to those involved in the project (clinicians and technicians). The key words used in the search were the following: cost of illness, cost, cost-benefit analysis, drug utilisation, prevalence, incidence, schizophrenia and mental disorder (see online supplementary appendix, table 1). Study titles were evaluated, including those published in peer-reviewed scientific journals, in Italian or English, reporting epidemiological or cost information preferably referring to the Italian context. Articles were selected and qualitatively analysed to identify information regarding any further aspects considering the treatment of schizophrenia that could be of interest for the purpose of current analysis (therapeutic pathways, health services and care provided at local level, etc). In order to reduce the possibility of report rejection, two investigators performed a blind reading of the materials, and any disagreement and risk of bias were solved through a discussion between the two review authors. ${ }^{23}{ }^{24}$ In the following paragraphs, we will first present the structure of the model and report the deterministic estimations for both the epidemiological and cost parameters. In conclusion, we will illustrate the statistical analysis that we performed in order to take into account the variability of the data used in the probabilistic model.

\section{Model structure}

A breakdown of the schizophrenic population was defined and then used to build the model (figure 1). This was based on the epidemiological and cost data identified through the systematic review.

As a first aspect, the literature showed that more than $74 \%$ of patients interrupted the treatment before

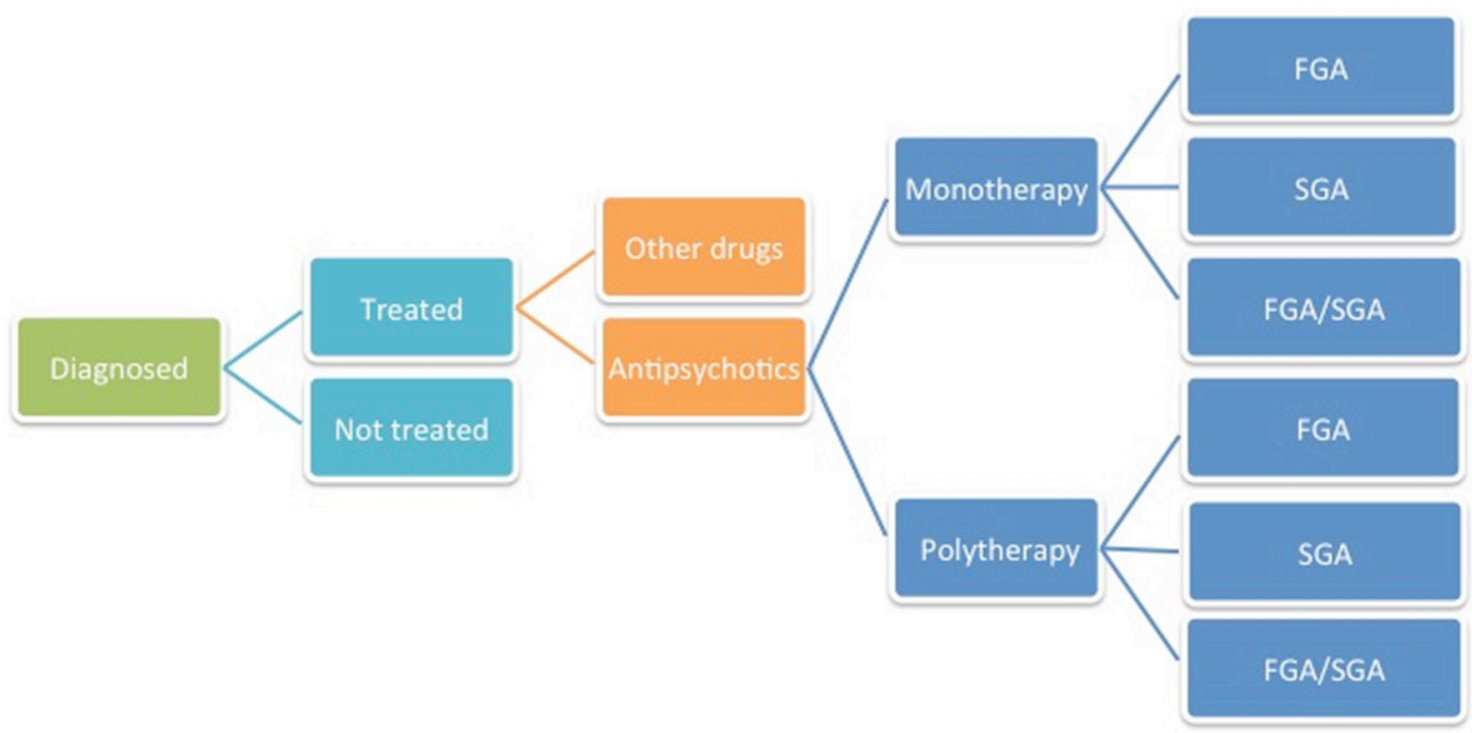

Figure 1 Breakdown of Col model. FGA, first-generation antipsychotics; SGA, second-generation antipsychotics. 
18 months. ${ }^{25}$ As previously indicated, in fact, only a percentage of diagnosed patients were actually identified and treated $(82.4 \%) .{ }^{26}$ On the same line, the treated patients (TF) were defined as "patients to whom a pharmacological treatment is prescribed and the drug is actually administered'. Vice versa, not treated patients (NTF) were defined as 'patients not receiving a prescription or not purchasing the prescribed drug'.

Second, data were broken down in relation to the categories of drugs that were currently administered: antipsychotic therapy (N05A) and other CNS (central nervous system) drugs therapy. The administration practice of antipsychotic was distinguished into monotherapy and polytherapy. According to this study, patients under monotherapy were 'subjects with a diagnosis of schizophrenia being treated with an antipsychotic without any additional concomitant CNS drugs within a year'. Patients under polytherapy corresponded to the "patients with only one antipsychotic treatment plus additional CNS drugs'. ${ }^{26}$ Therefore, in line with the National Ministerial Guidelines ${ }^{27}$ only the therapeutic switch between first-generation and second-generation antipsychotics (FGA/SGA) was considered and not the contemporary intake (off label) of more antipsychotics for the same psychiatric disorder.

The stratification of the population, used to inform the probabilistic model, is showed in figure 1. This was obtained considering the opinions of the experts involved in the project and the analysis of previous contributions in this field according to the results of the literature review.

\section{Epidemiological parameters}

Based on the systematic literature review, we considered the resident population in Italy on 1 January 2014, as estimated by the Italian National Statistics Institute. ${ }^{28}$ To this figure, a prevalence of schizophrenia in Italy estimated as $0.5 \%$ on the overall population was applied. This value was obtained considering the linear mean between the literature results and the expert opinion $(0.3 \%-0.7 \%)^{23}$ (online supplementary appendix, table 2 ).

The model assumed that $70 \%$ of the prevalent patients were actually diagnosed. This was obtained by making an average of the estimates reported by the Lazio Region in relation to the Mental Illness Centres (Centro di Salute Mentale-CSM) in $2012^{29}$ and the opinions of clinicians involved in the current analysis regarding the real practice of their centres. Furthermore, from a study that assessed costs due to the treatment of schizophrenia from the perspective of Lombardia Region, ${ }^{26}$ it was considered that $82.4 \%$ of the diagnosed subjects were actually in treatment (TF) (range 74.9\%-90.0\% ${ }^{26}$ and expert opinion), while $17.6 \%$ (range $25.1 \%-10.0 \%{ }^{26}$ and expert opinion) were not treated with antipsychotics or other drugs (NTF). According to these assumptions, patients being treated with monotherapy were estimated at $40 \%$ of the total number of treated patients with antipsychotics (range $20 \%-60 \%{ }^{30}$ ), while those under polytherapy accounted for $60 \%$ (range $\left.80 \%-40 \%^{30}\right)$. Patients being treated with antipsychotics were further broken down according to the type of drug. It was assumed that $30.3 \%$ of total patients (range $20.8 \%-39.7 \%^{26} 31$ ) were treated with FGA $^{2631}, 50.7 \%$ (range $37.6 \%-63.8 \%{ }^{26}{ }^{31}$ ) were treated with SGA and $19.1 \%$ (range $15.4 \%-22.7 \%^{26}{ }^{31}$ ) (online supplementary appendix, table 2 ) with a combination of FGA and SGA.

\section{Cost parameters}

Direct costs were calculated based on the following parameters: drugs, hospitalisations, residential and semiresidential facilities, and health specialist services such as psychotherapy and diagnostic examinations. In line with the Italian Ministry of Health, ${ }^{32}$ we distinguished between hospitalisations and residential facilities. The former are related to the management of acute events which require a variety of diagnostic and therapeutic options provided by hospitals. The latter provide assistance to the patients with stabilised clinical conditions who may require a long-term assistance, in relation to the chronicity of their illness. In Italy, this kind of services is coordinated at a local level by the Mental Illness Centres (CSM). Thus, in relation to the length of stay we were able to distinguish between residential facilities (Strutture residenziali) where patients can be assisted for more than $24 \mathrm{~h}$ and semiresidential facilities (Centri Diurni) for day care. ${ }^{33}$

Cost parameters used to inform the probabilistic model were calculated by the type of treatment (monotherapy, polytherapy). In the online supplementary appendix tables 3-5, data used to calculate cost parameters are reported. Additionally, parameters are illustrated in terms of drug categories (FGA, SGA, FGA/SGA), and the data from the sources selected through our systematic literature review are reported.

From a methodological point of view, literature data were mainly used to estimate SGA treatments, as more sources were available. To estimate 'Other drugs' and 'Not treated (NTF)' categories, only one literature source was taken into account. ${ }^{26}$ With reference to indirect costs, the loss of productivity of the patients and caregivers and the cost related to disability compensations were estimated. The loss of productivity was calculated in terms of missed access to the job market or unemployment rate caused by the disease. This was calculated by taking into account the differential between the percentage of unemployed people recorded in Italy in $2014^{34}$ and that reported in literature and related to the subjects affected by schizophrenia. ${ }^{8}{ }^{9}$ In this regard, the cost due to the higher unemployment rate was obtained by multiplying the prevalence of unemployed patients with schizophrenia by the average income of the Italian population. ${ }^{35}$ The term 'caregiver' is referred to those subjects, such as family members, who provide care to the patient. Costs may be due, for example, to, 'transportation to access treatment facilities and social care services'. ${ }^{26}$ To estimate the burden related to this category, we considered the number of workdays that these subjects ${ }^{10}$ spend in supporting the patients with schizophrenia. This value 
was multiplied by the Italian mean of income in $2014^{35}$ to calculate the (crude) amount of the resources lost/used by these subjects.

Finally, about $51 \%$ of the patients received a pension. ${ }^{8}$ This percentage was multiplied by the average of the disability compensations paid by the National Social Security Institute in Italy. ${ }^{36}$ More specifically, only the disability pensions-and not the attendance allowance or incapacity pensions paid by the State or other forms of financial support-were included. This permitted to obtain a more prudent estimate in line with the prevalence value indicated by the literature.

\section{Statistical analyses}

In order to consider the variability of the data used to inform the model, a probabilistic approach was used (probabilistic sensitivity analysis). The analysis consists of using the differences found in the examined sources indicating a minimum and maximum value of the uncertainty distribution of each parameter.

The probabilistic distribution was prepared applying what is normally reported for the development of probabilistic models in economic evaluations, distinguishing between costs (gamma distribution) and epidemiological parameters (beta distribution) ${ }^{37}$ Furthermore, the distribution of each parameter was used to perform 5000 Monte Carlo simulations to obtain interval estimates $(95 \% \mathrm{CI})$ of the main epidemiological and economic data.

Finally, in order to verify the uncertainty of the model, a one-way sensitivity analysis was performed, adjusting each parameter to the highest and lowest possible values of the data obtained in the systematic review of the literature. As average distribution value, the data of a particularly reliable source of the literature or the mean between minimum or maximum values were indicated, thus assuming an equal distribution of the values at the two extremes. This kind of analysis allows us to identify the parameters that mostly influence final cost variations associated with schizophrenia. The definition of 'possible' for the highest and lowest values deriving from the analysis of the literature might vary from model to model, but it is usually reasonable to vary the parameters according to the CIs of the data.

\section{RESULTS}

According to our model estimates, in Italy 212739 of subjects were diagnosed with schizophrenia in 2014. Of these, 175382 were in treatment $(82.4 \%)$, most of them $(86.5 \%)$ with antipsychotics mainly associated with other CNS drugs (polytherapy 60\%). About 57000 patients were unemployed (27\%) and 110000 received a pension from the National Social Security Institution-Italy (INPS) $(52 \%)$. Families and subjects taking care of the patients (caregivers) lost on average 44.1 working days a year in activities linked to the disease. According to the probabilistic estimates, the total cost of schizophrenia in Italy is $€ 2770495280$ (95\% CI €1771.93 to €3988.65). $50.5 \%$ of this amount is due to indirect costs, while the remaining $49.5 \%$ to direct costs linked to the disease.

Overall, almost $€ 1.37$ billion (average $1372779860 ; 95 \%$ CI $€ 850.88$ to $€ 2017.49$ ) were the direct costs caused by schizophrenia and incurred by the NHS (figure 2). Of these, $81 \%$ were related to the aggregate of expenses due to hospitalisation (€218 $855113 ; 95 \%$ CI $€ 131.14$ to $€ 328.67)$, residential facilities (€672 $640775 ; 95 \%$ CI $€ 397.37$ to $€ 1019.18$ ) and semiresidential facilities (€217 746 132; 95\% CI $€ 134.96$ to $€ 320.02)$. The drugs accounted for $10 \%$ (figure 2) with a yearly average expense of $€ 135911253$ $(95 \%$ CI $€ 82.05$ to $€ 203.14)$. Health specialist services corresponded to $9 \%, € 127626587$ (95\% CI $€ 78.38$ to $€ 188.69)$.

Specifically, figure 3 and table 1 report the direct costs broken down by type of therapy. The patients in polytherapy accounted for $€ 446.85$ billion (95\% CI $€ 259.31$ to $€ 684.61), 53 \%$ of total costs of patients in treatment. The estimate of patients in monotherapy (33\% of treated patients) is 272.92 billion (95\% CI $€ 139.04$ to $€ 451.19)$. For 'Other CNS drugs' and not treated patients, the expenses highlighted by the model accounted for 115.78 billion (95\% CI $€ 75.78$ to $€ 164.13$ ) and 537.21 billion (95\% CI €291.94 to €856.05). Figure 3 shows the breakdown of the expenses according to the therapy followed by patients with schizophrenia. In case of monotherapy and polytherapy, the main expense item was that of semiresidential facilities, accounting for $26 \%$ and $24 \%$ of the total respectively, followed by hospitalisation (24\% monotherapy, $23 \%$ polytherapy) and drugs

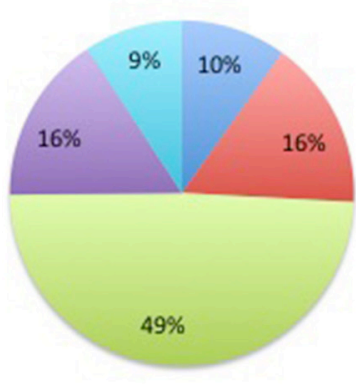

\begin{tabular}{|c|c|c|}
\hline Cost parameter & Mean & Cl 95\% [Min-Max] \\
\hline Drugs & $€ 135.91$ & $(€ 82.05-€ 203.14)$ \\
\hline Hospitalisations & $€ 218.86$ & $(€ 131.14-€ 328.67)$ \\
\hline Residential facilities & $€ 672.64$ & $(€ 397.37-€ 1,019.18)$ \\
\hline Semi-residential facilities & $€ 217.75$ & $(€ 134.96-€ 320.02)$ \\
\hline Health specialist services & $€ 127.63$ & $(€ 78.38-€ 188.69)$ \\
\hline
\end{tabular}

Figure 2 Direct costs and probabilistic results (95\% Cl), Euro million. 


\section{Monotherapy}

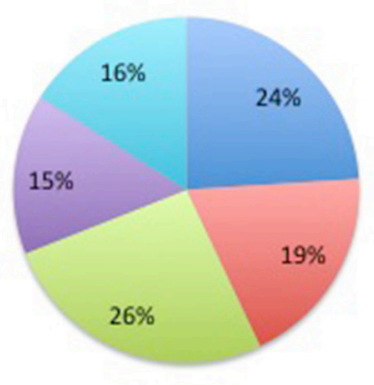

Other drugs

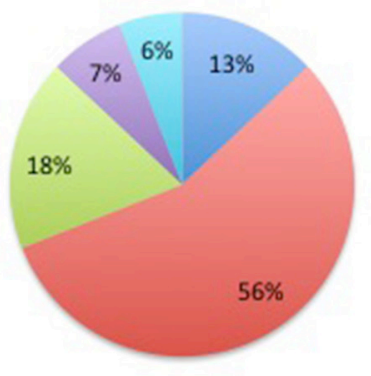

- Hospitalisations

Health care services

\section{Polytherapy}

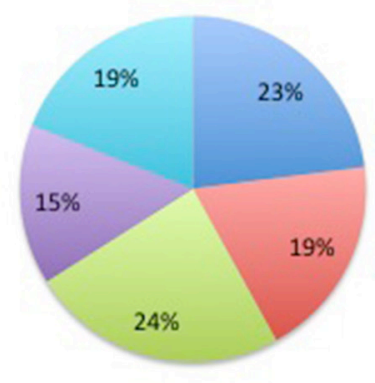

Not Treated

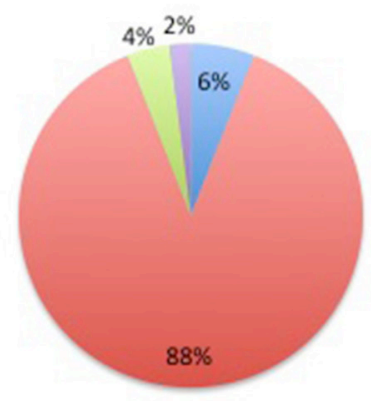

Semi residential facilities

Figure 3 Direct costs per year, Italy.

(16\% monotherapy, 19\% polytherapy). Furthermore, 88\% (473.1 billion; $95 \%$ CI $€ 257.1$ to $€ 753.89$ ) of the costs of those patients who were not treated corresponded to the residential facilities that also accounted for $39 \%$ of the total direct costs. On the other hand, residential facilities corresponded to $56 \%$ of costs related to patients treated with other CNS drugs ( 64.9 billion; $95 \%$ CI $€ 42.48$ to $€ 92)$.
With reference to the indirect costs, the model estimated an overall expense of $€ 1397715421 \quad(95 \%$ CI $€ 869.7$ to $€ 2048.97)$. The main cost item was that related to the loss of productivity, accounting for about $60 \%$ of total indirect costs. The costs referred to the caregiver's loss of productivity were $11 \%$ of the total indirect costs, while pension costs were $29 \%$ of the burden (figure 4).

\begin{tabular}{|c|c|c|c|c|}
\hline Cost item (mean annual cost) & $\begin{array}{l}\text { Monotherapy } \\
\text { (Euro million) }\end{array}$ & $\begin{array}{l}\text { Polytherapy } \\
\text { (Euro million) }\end{array}$ & $\begin{array}{l}\text { Other drugs } \\
\text { (Euro million) }\end{array}$ & $\begin{array}{l}\text { Not treated } \\
\text { (Euro million) }\end{array}$ \\
\hline Hospitalisation $(95 \% \mathrm{Cl})$ & $\begin{array}{l}€ 65.96 \\
(€ 29.19 \text { to } € 117.49)\end{array}$ & $\begin{array}{l}€ 104.20 \\
(€ 57.17 \text { to } € 165.13)\end{array}$ & $\begin{array}{l}€ 15.04 \\
(€ 9.85 \text { to } € 21.33)\end{array}$ & $\begin{array}{l}€ 33.63 \\
(€ 18.28 \text { to } € 53.6)\end{array}$ \\
\hline Semiresidential facilities $(95 \% \mathrm{Cl})$ & $\begin{array}{l}€ 70.61 \\
(€ 36.69 \text { to } € 115.46)\end{array}$ & $\begin{array}{l}€ 106.07 \\
(€ 62.08 \text { to } € 161.67)\end{array}$ & $\begin{array}{l}€ 20.94 \\
(€ 13.71 \text { to } € 29.69)\end{array}$ & $\begin{array}{l}€ 20.1 \\
(€ 10.93 \text { to } € 32.04)\end{array}$ \\
\hline Health specialist services $(95 \% \mathrm{Cl})$ & $\begin{array}{l}€ 41.11 \\
(€ 21.12 \text { to } € 67.67)\end{array}$ & $\begin{array}{l}€ 68.36 \\
(€ 39.66 \text { to } € 104.75)\end{array}$ & $\begin{array}{l}€ 7.78 \\
(€ 5.09 \text { to } € 11.03)\end{array}$ & $\begin{array}{l}€ 10.36 \\
(€ 5.63 \text { to } € 16.51)\end{array}$ \\
\hline
\end{tabular}



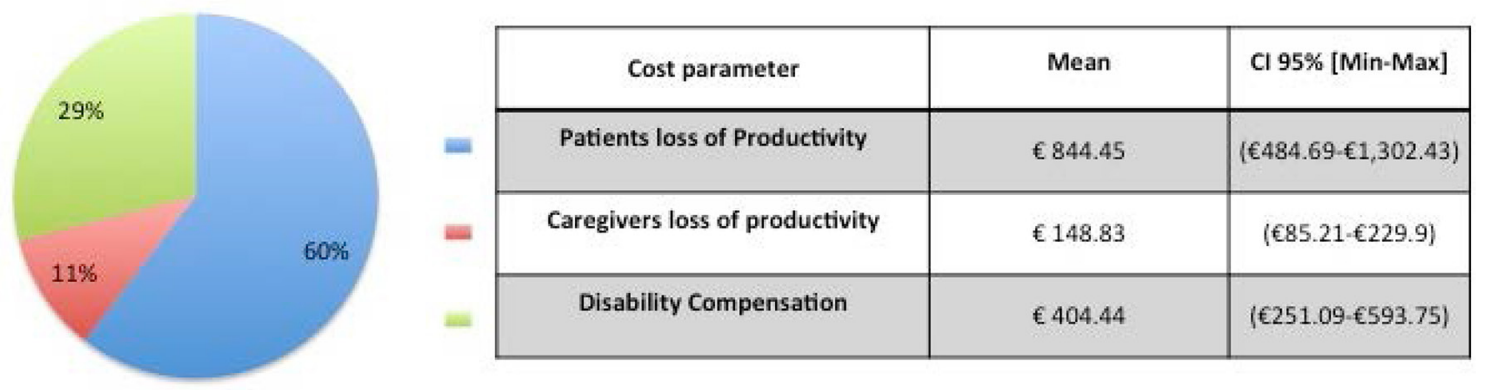

Figure 4 Indirect costs and probabilistic results $(95 \% \mathrm{Cl})$, Euro million.

Figure 4 reports the data of the expenses indirectly linked to the disease in diagnosed subjects. The main item was that of the patients' loss of productivity $€ 844448270$ (95\% CI $€ 484.69$ to $€ 1302.43)$. The estimates of the pension burden (National Social Security InstitutionItaly (INPS) disability compensations) amounted to $€ 404436141$ (95\% CI €251.09 to €593.75). Finally, the third expense item ( $11 \%$ of total indirect costs) is linked to the 'lost' work days of the caregiver, corresponding to $€ 148831009$ (95\% CI $€ 85.21$ to $€ 229.9)$.

\section{DISCUSSION}

The study's aim was to quantify the yearly mean cost for the care and management of the patients with schizophrenia in Italy. Consequently, in addition to the epidemiological relevance on total population $(0.5 \%)$, decision-makers shall also take into account the significant economic impact of this disease. The results of our work, indeed, confirmed those of international literature about costs. They indicate that in Italy the total cost for society was approximately $€ 2.7$ billion. The need to quantify the impact of schizophrenia in Italy was due to the variety of the possible therapeutic pathways and the different approaches and methods in using FGA/SGA.

First of all, the breakdown of the expense for the care and management of schizophrenia showed the relevance of the indirect costs associated with it (€6614 per capita yearly), about $€ 1.4$ billion totally estimated by the model. These costs shall be duly taken into account, especially for diseases, such as schizophrenia, which require constant daily care and support by the families and society as a whole. It should be also considered that, according to international studies, schizophrenia is one of the first 10 causes of severe and chronic disability. ${ }^{6} 1038$ With reference to this, two main forms of care for schizophrenic subjects were identified and considered as a measure of the burden caused by the disease. First, we considered the care provided by the patient's family (€689 per capita yearly, on average); second, we measured the support provided through the National Social Security Institution-Italy (INPS) that was about $€ 1863$ yearly on average. Finally, we also identified the effect of the disease directly related to patients, impeding and hindering the access to the job market (€4062).
A key issue raised by the study concerned the number of not treated patients (NTF) involving an economic burden of over $€ 14000$ per capita a year, compared with a mean of $€ 4000$ for treated patients. In terms of direct costs, untreated patients accounted for $40 \%$ of the total expense, even if they only represent $17.6 \%$ of the total diagnosed patients. With respect to the total economic burden, not treated patients (NTF) caused an annual expense of about $€ 493$ million only for residential and semiresidential facilities (18\% of total expense of schizophrenia in Italy) and over $€ 43.7$ million for hospitalisation and health specialist services. To our knowledge, this is the first study conducted in Italy estimating the total impact of schizophrenia using data from a systematic literature review and expert opinion. Based on this, a probabilistic model was built, obtaining a macro value of the economic impact of schizophrenia in Italy. For diseases such as schizophrenia, often presenting conflicting guidelines and behaviours in the clinical practice, the analysis of the real practice is fundamental to correctly identify significant characteristics considered in this context. This is what emerged from main studies referred to Italy that were taken into account in building the cost and epidemiological parameters included in the model. However, being mostly observational parameters, ${ }^{10} 2630$ focused on specific types of treatments and care pathways linked to local reality, they did not help in obtaining a global estimate of the specific aspects of schizophrenia and its total impact in terms of the resources used. Therefore, current analysis was exclusively referred to schizophrenia as identified with codes ICD10 (International Classification of Diseases, 10th edition) and not to the wider category of mental disorders. In addition to this, indirect costs were specifically analysed considering those presented as a significant cost item in literature, but never analysed in depth, in terms of its components.

One limit of the study may be the standardisation of the retrieved data required to break down the population. As highlighted in previous studies and by the information provided by the experts, the population breakdown was focused on the main expense items to be associated with NHS in Italy. The review allowed systematising the available information, but this may not be representative of the real practice on a national level. To fill this gap, the 
model proposed a well-validated probabilistic estimate method, ${ }^{13-22}$ considering the variability in the literature as minimum and maximum range in which it was highly possible to obtain the real inference estimate.

A second limit may be identified in the impossibility to obtain epidemiological sources and cost data from registry and/or administrative national data. Unfortunately, these data are very difficult to be retrieved in Italy, where the fragmentary information at a regional level and the heterogeneity of the data collected do not allow to obtain adequate and representative samples.

Finally, there is an ongoing debate on whether disability pension should be included in the estimation of indirect costs. ${ }^{39}$ The criticism is referred to the possibility that they represent a transfer payment and their inclusion may result in a double counting estimation of the real economic burden from the perspective of the taxpayer rather than society. However, the Ministry of Economy through the general taxation funds disability pensions in Italy while the Social Security Institution-INPS is in charge of their disbursement.

\section{CONCLUSION}

In conclusion, this work represents a first attempt to fill the information gap on the yearly total expense and the cost breakdown of NHS and society to cure, treat and manage the patients affected with schizophrenia in Italy. These estimates may represent a useful tool for national and regional decision-makers to implement treatment policies and manage the patients in line with the specific context.

Contributors AM: conception and design of study. GF: data collection and drafting of the manuscript. RV: data collection. PCFM, AS, GN: served as scientific advisors. FSM: critically reviewed the study proposal.

Funding The study was supported with unrestricted funding from Jannsen, Italy. Competing interests None declared.

Patient consent Not required.

Provenance and peer review Not commissioned; externally peer reviewed.

Data sharing statement There are no unpublished data available.

Open Access This is an Open Access article distributed in accordance with the Creative Commons Attribution Non Commercial (CC BY-NC 4.0) license, which permits others to distribute, remix, adapt, build upon this work non-commercially, and license their derivative works on different terms, provided the original work is properly cited and the use is non-commercial. See: http://creativecommons.org/ licenses/by-nc/4.0/

(C) Article author(s) (or their employer(s) unless otherwise stated in the text of the article) 2018. All rights reserved. No commercial use is permitted unless otherwise expressly granted.

\section{REFERENCES}

1. Gustavsson A, Svensson M, Jacobi F, et al. Cost of disorders of the brain in Europe 2010. Eur Neuropsychopharmacol 2011;21:718-79.

2. Tansella M, De Girolamo G. La diffusione dei disturbi mentali nella comunità. Roma: Dipartimento di Medicina e Sanità Pubblica, Sezione di Psichiatria, Università di Verona; Progetto Nazionale Salute Mentale, Laboratorio di Epidemiologia, Istituto Superiore di Sanità, 2005.
3. Saha S, Chant D, Welham J, et al. A systematic review of the prevalence of schizophrenia. PLoS Med 2005;2:e141.

4. Altamura C, Galderisi P, Rocca A, et al. Schizophrenia today: epidemiology, diagnosis, course and models of care. Ital J Psychopathol 2014;20:223-43.

5. Altamura AC, Serati M, Albano A, et al. An epidemiologic and clinical overview of medical and psychopathological comorbidities in major psychoses. Eur Arch Psychiatry Clin Neurosci 2011;261:489-508.

6. Knapp M, Mangalore R, Simon J. The global costs of schizophrenia. Schizophr Bull 2004;30:279-93.

7. Rocca P, Giugiaro M, Bogetto F. Compliance in the treatment of schizophrenia. Rivista di psichiatria 2006.

8. Garattini L, Barbui C, Clemente R, et al. Direct costs of schizophrenia and related disorders in Italian community mental health services: a multicenter, prospective 1-year followup study. Schizophr Bull 2004;30:295-302.

9. Garattini L, Rossi C, Tediosi F, et al. Direct costs of schizophrenia in Italian community psychiatric services. Pharmacoeconomics 2001;19:1217-25.

10. Cortesi PA, Mencacci C, Luigi F, et al. Compliance, persistence, costs and quality of life in young patients treated with antipsychotic drugs: results from the COMETA study. BMC Psychiatry 2013:13:98.

11. Niolu C, Barone Y, Bianciardi E, et al. Predictors of poor adherence to treatment in inpatients with bipolar and psychotic spectrum disorders. Riv Psichiatr 2015;50:285-94.

12. Niolu C, Bianciardi E, Di Lorenzo G, et al. Enhancing adherence, subjective well-being and quality of life in patients with schizophrenia: which role for long-acting risperidone? Ther Adv Psychopharmacol 2015;5:278-88.

13. Marcellusi A, Mecozzi A, Mennini FS. Direct and indirect cost of diabetes in italy: a prevalence probabilistic approach: CEIS Tor Vergata Research paper series, 2014.

14. Baio G, Capone A, Marcellusi A, et al. Economic burden of human papillomavirus-related diseases in Italy. PLoS One 2012;7:e49699.

15. Marcellusi A, Viti R, Capone A, et al. Costi diretti e indiretti assorbiti dalle patologie HCV-indotte in Italia: stima basata su una metodologia probabilistica di cost of illness. PharmacoEconomics Italian Research Articles 2014;16:1-10.

16. Marcellusi A, Viti R, Capone A, et al. The economic burden of HCVinduced diseases in Italy. A probabilistic cost of illness model. Eur Rev Med Pharmacol Sci 2015;19:1610-20.

17. Marcellusi A, Viti R, Incorvaia C, et al. [Direct and indirect costs associated with respiratory allergic diseases in Italy. A probabilistic cost of illness study]. Recenti Prog Med 2015;106:517-27.

18. Marcellusi A, Viti R, Mecozzi A, et al. The direct and indirect cost of diabetes in Italy: a prevalence probabilistic approach. Eur J Health Econ 2016;17.

19. Marcellusi A, Viti R, Sciattella P, et al. Economic aspects in the management of diabetes in Italy. Value Health 2015;18:A602-A603.

20. Russo S, Mariani TT, Migliorini R, et al. The economic burden of musculoskeletal disorders on the Italian social security pension system estimated by a Monte Carlo simulation. Reumatismo 2015;67:45-56.

21. Russo S, Viti R, Marcellusi A, et al. Direct and indirect costs associated to retinal vascular diseases in Italy. A probabilistic cost of illness study. Value Health 2015;18:A418.

22. Fabriani V, Marcellusi A, Mennini FS, et al. Cost of illness analysis of duchenne muscular dystrophy In Italy. Value Health 2014;17:A528.

23. Moher D, Liberati A, Tetzlaff J, et al. Reprint--preferred reporting items for systematic reviews and meta-analyses: the PRISMA statement. Phys Ther 2009;89:873-80.

24. Moher D, Liberati A, Tetzlaff J, et al. Preferred reporting items for systematic reviews and meta-analyses: the PRISMA statement. J Clin Epidemiol 2009;62:1006-12.

25. Lieberman JA, Stroup TS, McEvoy JP, et al. Effectiveness of antipsychotic drugs in patients with chronic schizophrenia. $N$ Engl $J$ Med 2005;353:1209-23.

26. Ravasio R, Sanfilippo L, De Paoli G, et al. I costi della schizofrenia in Italia: i risultati di un'analisi condotta nell'ASL della Provincia di Pavia. Giornale Italiano di Health Technology Assessment 2009;2:19-28.

27. Salute MD. Gli interventi precoci nella schizofrenia, in Sistema nazionale per le linee guida, 2009.

28. ISTAT. http://demo.istat.it/pop2015/index.html. 2015.

29. Gaddini A, Arcà M, Fratini S. Rapporto sull'attività dei Centri di Salute Mentale, dei Centri Diurni e delle Strutture Residenziali psichiatriche del Lazio: ASP Regione Lazio, 2014. 
30. Degli Esposti L, Sangiorgi D, Mencacci C, et al. Pharmaco-utilisation and related costs of drugs used to treat schizophrenia and bipolar disorder in Italy: the IBIS study. BMC Psychiatry 2014;14:282.

31. Santone G, Bellantuono C, Rucci P, et al. Patient characteristics and process factors associated with antipsychotic polypharmacy in a nationwide sample of psychiatric inpatients in Italy. Pharmacoepidemiol Drug Saf 2011;20:441-9.

32. Ministero della Salute. Le strutture residenziali psichiatriche: Accordo conferenza unificata, 2013.

33. Ministero della Salute. I servizi di salute mentale. $2016 \mathrm{http}: / / w w w$. salute.gov.it/portale/temi/p2_6.jsp?id=168\&area=salute+mentale\& menu=rete

34. ISTAT. Occupati e disoccupati (media 2014). 2014 http://www.istat.it/ it/archivio/149085.
35. OCSE. Average annual wages. $2014 \mathrm{http}: / /$ stats.oecd.org/Index. aspx?DataSetCode=AV_AN_WAGE.

36. INPS. Prestazioni agli Invalidi Civili Serie storica. 2014 http://www.inp s.it/webidentity/banchedatistatistiche/vig12/index.jsp.

37. Briggs AH, Claxton K, Sculpher MJ. Decision modelling for health economic evaluation. Oxford handbooks in health economic evaluation. Oxford: Oxford University Press, 2006:237.

38. Rössler W, Salize HJ, van Os J, et al. Size of burden of schizophrenia and psychotic disorders. Eur Neuropsychopharmacol 2005;15:399-409.

39. Frisman L. How transfer payment are treated in cost-effectiveness and cost- benefit analyses Administration and Policy in Mental Health, 1996;23. 